Ankara Ecz. Fak. Mec.

13. 159 (1983)
J. Fac. Pharm Ankara

13159 (1983)

\title{
Güney Anadolu'nun Bazı Allium Türleri (Sect.Melanocrommyum) Üzerinde Sitotaksonomik Araştırmalar
}

\author{
Gytotaxonomic Studies on Some Allium Species
}

(Sect. Melanocrommyum) of South Anatolia

Mehmet KOYUNCU* Neriman ÖZHATAY**

\begin{abstract}
Allium cinsi Türkiye'de hemen hemen 150 kadar tür ile temsil edilir. Bu cinsin Melanocrommyum seksiyonunda Türkiye'de bulunan türlerinin adedi ise 13 civarındadır. Bu seksiyondaki türler, yer yüzünde genel olarak Akdeniz bölgesinde yayılmışlardır ve yayılış merkezleri Doğu Akdeniz, muhtemelen Türkiye'dir (1).
\end{abstract}

$\mathrm{Bu}$ çalışmada Güney Anadolu'dan toplanan Melanocrommyum seksiyonundaki türlerin morfolojik özellikleri ve karyotipleri incelenmiştir.

\section{MATERYAL ve YÖNTEM}

Güney Anadolu'da doğal yetişme ortamlarından toplanan $A l$ lium örneklerinin bir kısmı kurutularak herbaryum materyali haline getirilmiş, diğer bir kısmı ise bahçeye dikilerek sitolojik araştırmalarda kullanılmıştır. Örnekler A. Ü. Eczacılık Fakültesi Herbaryumunda (AEF) bulunmaktadir. Sitolojik incelemelerde kullanılan metod ÖZHATAY'ın çalışmasında (2) verildiği şekildedir. Kromozomların çizimleri Leitz SM-Lux binoküler mikroskobunda resim çizme tübü yardımıyla yapılmıştır. Kromozom tipleri LEVAN ve arkadaşları (3) tarafından verilen aşağıdaki hesaplara göre saptanmıştır.

Redaksiyona verildiği tarih: 3 Haziran 1983

* Farmasötik Botanik Bilim Dalı, Eczacılık Fakültesi, Ankara Üniversitesi.

** Farmasötik Botanik Bilim Dalı, Eczacılık Fakültesi, İstanbul Üniversitesi. 
$\mathrm{r}=1 / \mathrm{s} .1=$ kromozomun uzun kolunun boyu, $\mathrm{s}=$ kromozomun kisa kolunun boyu. $\mathrm{r}=1.0-1.7$ ise kromozom metasentrik, $\mathrm{r}=1.7-3.0$ ise kromozom submetasentrik, $\mathrm{r}=3.0-7.0$ ise kromozom akrosentrik veya subtelosentriktir. $r$ değeri yardımıyla şekilleri bulunan kromozomlar sentromerleri aynı düzlemde olmak üzere soldan sağa, metasentrikten akrosentriğe doğru dizilmiş ve 1-8'e kadar numaralanmıştır.

\section{BULGULAR}

Güney Anadolu Bölgesinde seksiyon Melanocrommyum'un kapsamına giren 6 türün yetiştiği saptanmıştır. Bu türlerin tanıtımı, yayılışları ve karyotipleri aşă̆ıda verilmiştir.

1. A. nigrum L., Sp. P1. ed. 2, 430 (1762). Şekil 1 a.

Soğan 2.5-4 cm çapında, ovoid; dış tunika koyu gri renkli, kabuksu, bazen soğancıklı. Skapus 60-90 cm boyunda, yuvarlak, çıplak. Yapraklar 3-4, hepsi tabanda, 5-5.5 cm eninde, geniş lanseolat, akut. Spata ovat, 3-4 parçaya ayrılmıs, valvler $3 \mathrm{~cm}$ kadar, dar, triangular, akuminat, kalıcı. Umbella 5-10 cm çapında, yarıküremsi, çok çiçekli; pediseller 25-45 $\mathrm{mm}$ boyunda, hemen hemen birbirine eşit, çiçeklerin 2-4 katı uzunlukta. Tepáller çiçek açma zamanında yıldız şeklinde, sonradan geri kıvrık, beyaz veya pembe renkli, orta damar yeşilimsi, 6-9 X 1.5-3.5 mm, oblong, diş tepal iç tepallerden biraz geniş, obtus. Filamentlerin hepsi basit, 3-5 $\mathrm{mm}$ boyunda, tepallerin yarısı kadar, tabanda halka şeklinde birleşik ve geniş, tepeye doğru daralır, beyaz; anterler sarı, $2 \mathrm{~mm}$ boyunda. Ovaryum küremsi, koyu yeşil veya siyahımsı renkli, üzeri tüberküllü, sapsız; stilus 1-2 mm boyunda; stigma tam. Kapsül 6-8 mm çapında, küresel; tohumlar 4-4.5 mm büyüklükte, düzensiz köşeli, üzeri papilli ve karışık. NisanMayıs'ta çiçek açar. 200-1200 m'ler arası tarla veya boş, düz alanlarda yetişir.

Yayılısı: Akdeniz Bölgesi, Güney Avrupa, Kuzey Afrika, Kıbrıs, Lübnan, Türkiye (Trakya, Batı ve Güney Anadolu).

İncelenen örnekler: C5 İÇEL: Tarsus, Çamliyayla (Namrun), Belçınar Köyü çevresi, tarlalar, 950 m,,Koyuncu AEF 5737! C6. ANTAKYA: Dursunlu Köyü çevresi, tarlalar, 200 m, Koyuncu ve ark. AEF 1363! İskenderun, Amanos Da., Akman 245! 

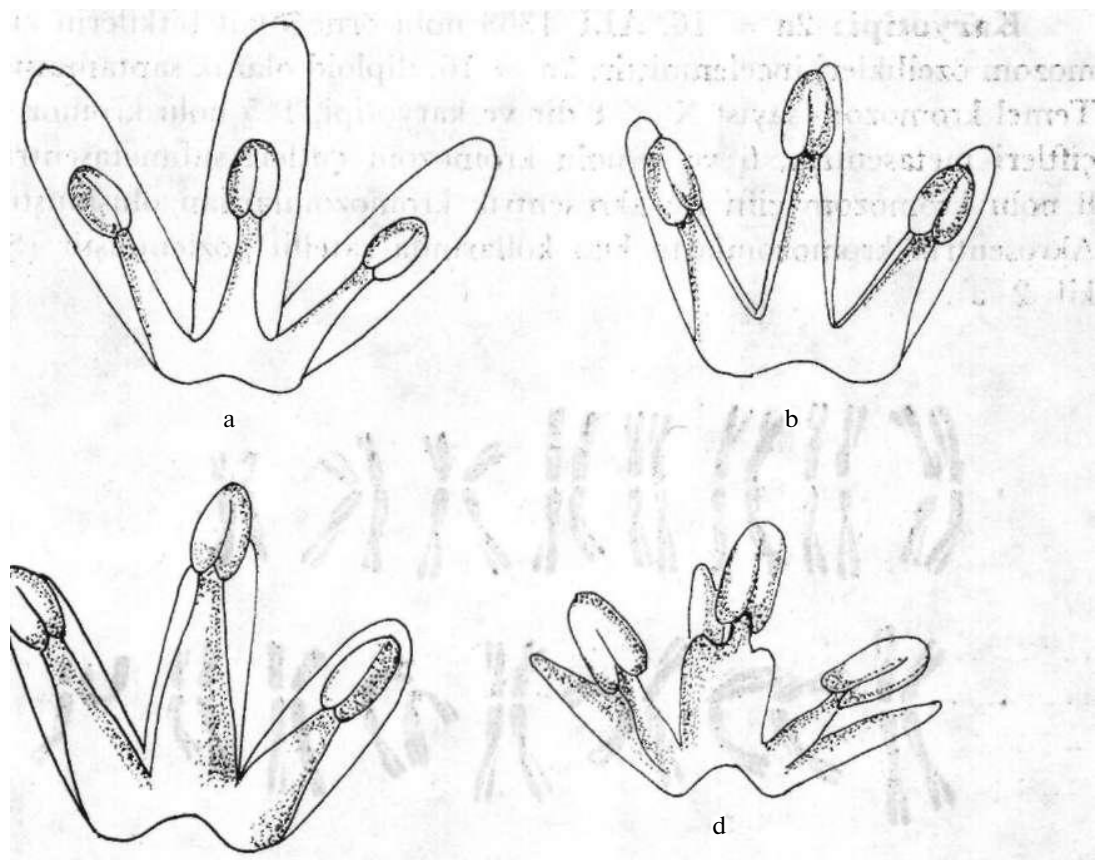

b

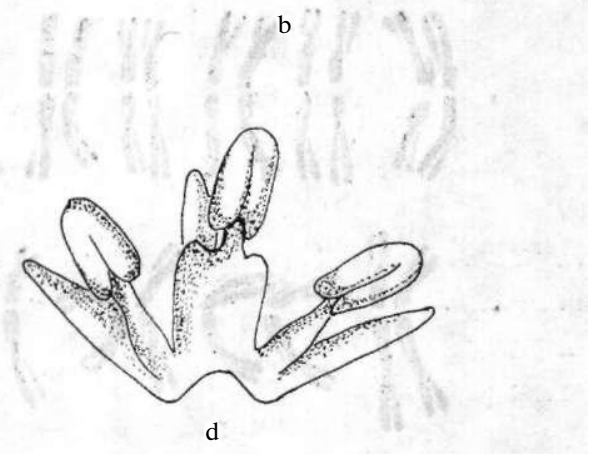

c

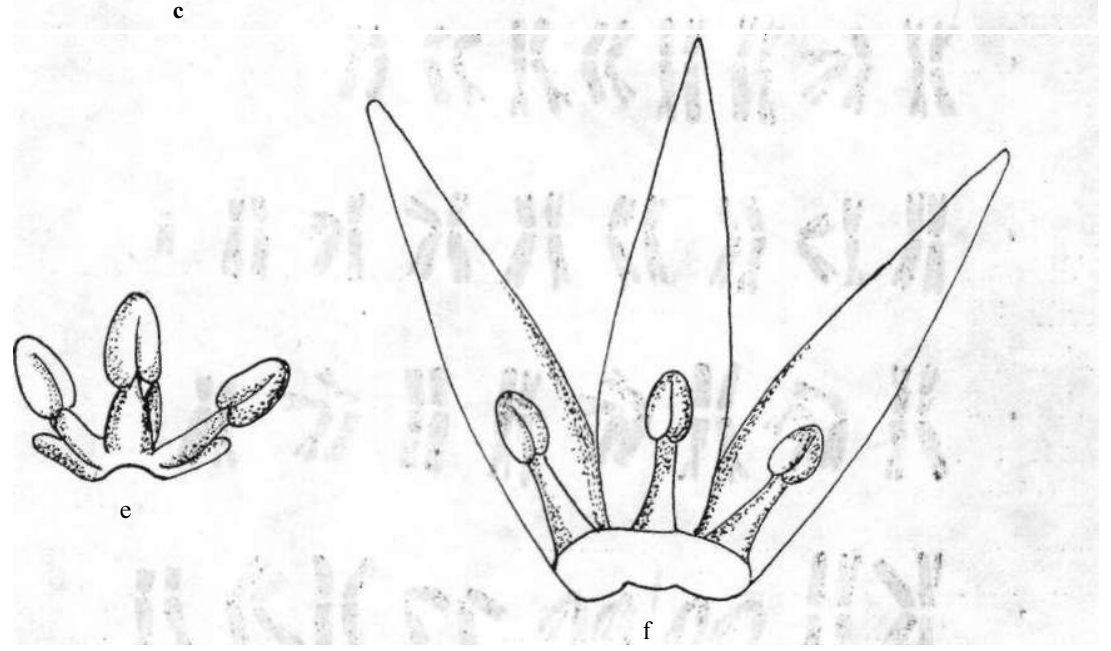

Şekil 1. Sect.Melanocrommyum: Tepaller ve Stamenler.

a-Allium nigrum b-A.stenopetalum, c- A.lycaonicum, d-A.cardiostemon,. e- Achryşantherum, f- A.karamanoglui (x6). 
Karyotipi: $2 \mathrm{n}=16$. AEF 1363 nolu örneğe ait bitkilerin kromozom özellikleri incelenmiştir. $2 \mathrm{n}=16$, diploid olarak saptanmıştır. Temel kromozom sayısı $\mathrm{X}=8^{\prime}$ dir ve karyotipi, $1-5$ nolu kromozom çiftleri metasentrik, 6 ve 7 nolu kromozom çiftleri submetasentrik, 8 nolu kromozom çifti ise akrosentrik kromozomlardan oluşmuştur. Akrosentrik kromozomların kısa kollarında satellit gözlenmiştir (Şekil 2 a).
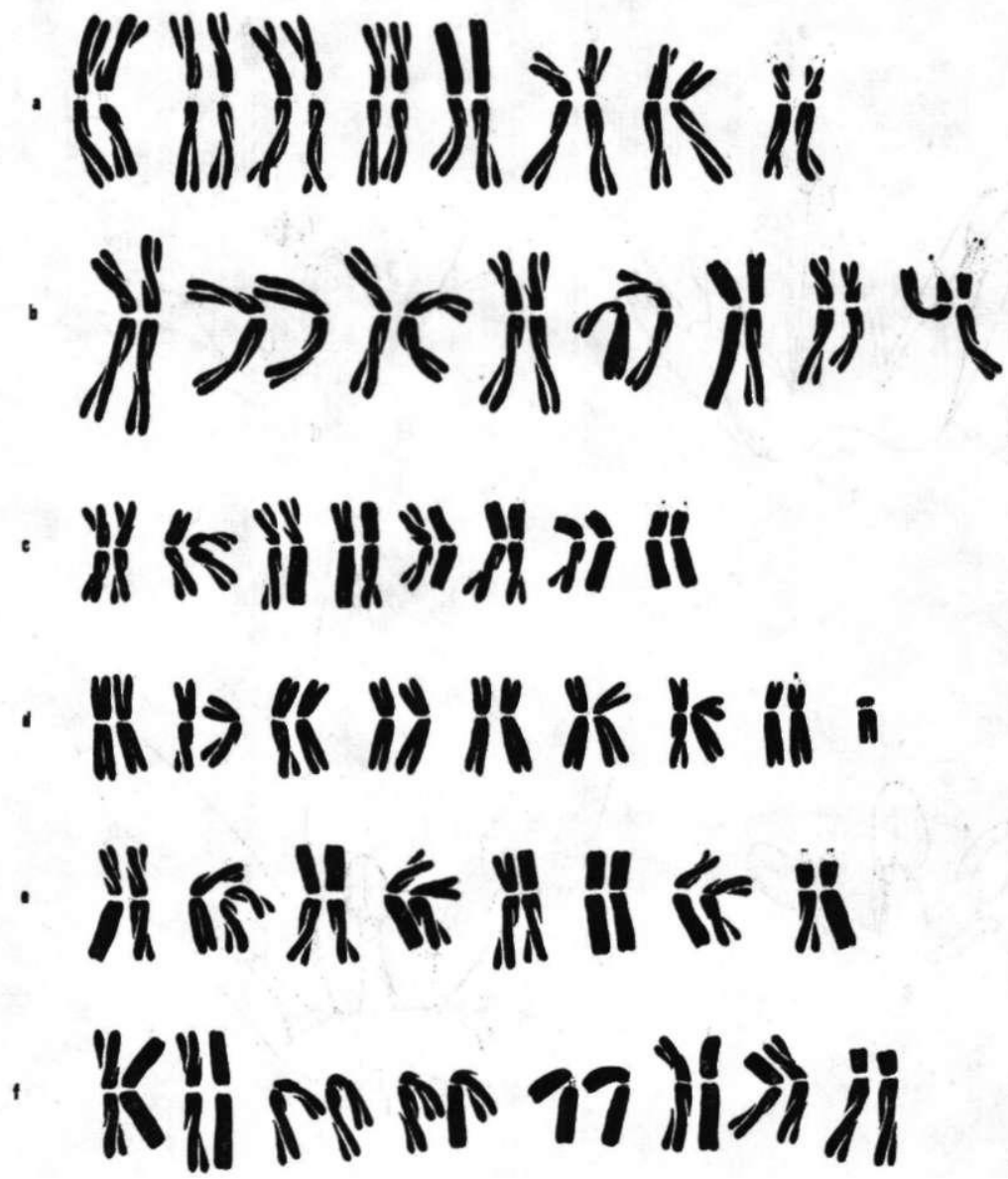

Şekil 2. Sect.Melanocrommyum: Karyotipler.

a- Allium nigrum $2 \mathrm{n}=16$, b-A.stenopetalum $2 \mathrm{n}=16$, c-A.lycaonicum $2 \mathrm{n}=16$, d- A. chrysantherum $2 \mathrm{n}=16+1 \mathrm{~B}$, e- A.cardiostemon $2 \mathrm{n}=16$, f- A.karamanoglui $2 \mathrm{n}-16(\mathrm{x} 1500)$. 
Bu türün kromozom sayımı Türkiyeden (Sivri Dağ) toplanmış örneklerden PEDERSEN ve VVENDELBO (6) tarafından $2 \mathrm{n}=16$ olarak verilmiştir. Avrupa'da yaygın olan bu türün kromozomları çeşitli araştırıcılar tarafından da $2 \mathrm{n}=16$ olarak sayılmıştır (4, 5, 7-9).

A. nigrum, Avrupa ve Trakya'da yetişen $A$. cyrilli Ten ve $A$. atropurpureum Waldst.et Kit. türlerine benzemektedir. Tepallerinin lanseolat ve obtus oluşu ile $A$. cyrilli'den; an terlerinin sarı, tepallerinin beyaz veya açık pembe rengi nedeniyle de $A$. atropurpureum'dan farklidir.

2. A. stenopetalum Boiss. et Ky. Excico. Gillic. Kurd. (1859). (Şekil 1 b).

Soğan 1-3 cm çapında, ovoid veya hemen hemen globoid, soğancık taşımaz; dış tunika koyu gri renkli. Skapus $8-30 \mathrm{~cm}$, silindirik. Yapraklar 2-5, hepsi tabanda, 6-20 cm X 5-15 mm, yassi, linearlanseolat, kenarları hafif skabroz, skapustan kısa veya hemen hemen ona eşit, nadiren az uzun, akuminat. Spata 2-4 valvli, valvler ovat, akuminat, umbelladan kısa, sonradan geriye kıvrık, kalıcı. Umbella 2-3 cm çapında, sık ve çok çiçekli, hemen hemen küresel; pediseller ince, $1.5-2 \mathrm{~cm}$ uzunlukta. Perigon çiçek açma zamanında yıldız şeklinde, sonradan geriye kivrık; tepaller leylak renginde, 5-6 X 1-1.5 $\mathrm{mm}$, dar linear, obtus. Filamentler perigonun $3 / 4$ ü uzunlukta, yassi, tabanda geniş, tepeye doğru daralır; anterler koyu kahverengi. Ovaryum küresel ya da basık küresel, stigma tam. Kapsül 5-6 mm çapında, küresel; tohumlar $2 \mathrm{~mm}$, üç köşeli, yüzeyi papilli. NisanMayıs aylarında çiçek açar. 850-1800 m'ler arası, dağlık yörelerde ve tarla içleri ile düz taşlı alanlarda yetişir.

\section{Yayılışı: Endemik* (Mersin, Adana ve Isparta çevreleri).}

İncelenen örnekler: C3 ISPARTA: Eğridir, Anamas, Zindan Dere, $1300 \mathrm{~m}, \mathrm{Ko}-$ yuncu ve Coşkun, AEF 6102! C5 İ ÇEL: Kuzucubelen, tarla, 700 m, Koyuncu, AEF 6090! ADANA: Gülek Boğazının kuzey yakası, 1800 m, Hennipman et al. 1276! Tarsus-Çamlıyayla (Namrun), Belçınar Köyü çevresi, tarlalar, 850 m, Кoyuncu, AEF 6072!

* Suriye'de yetiştiği kaydedilmekle birlikte, bunun doğrulanması gerektiğine işaret edilmektedir (10). 
Karyotipi : $2 \mathrm{n}=16$. AEF 6072 nolu örnek üzerinde stiolojik araştırma yapılmıştır. Diploid bir türdür. Temel kromozom sayısı $\mathrm{X}=8$ 'dir ve 1-7 nolu kromozomlar metasentrik-submetasentrik, 8 nolu kromozom çifti ise akrosentriktir ve akrosentrik olan kromozomlar kısa kollarında Satellit taşır. 1 ve 7 nolu kromozomların çiftleri arasında heteromorfi görülmektedir (Şekil 2 b). Bu türün kromozom sayısı ve morfolojisine ait daha önce yapılmış bir çalışmaya rastlanmamıştır.

A. lycaonicum Siehe'a çok benzeyen bu tür soğanının etrafında soğancık taşımaması, tepallerinin dar linear ve leylak rengi, ovaryumunun da küresel oluşu ile farklıdır.

3. A. Iycaonicum Siehe in Ann. Nat. Hofmus. Wien, 28: 185 (1914). Şekil 1 c.

Soğan 1.5-2.5 cm çapında, ovoid, küçük sarı renkli soğancıklar taşır; dış tunika kabuksu, beyazımsı-gri renkli. Skapus 20-30 ( -50$)$ cm, çıplak, dik, silindirik. Yapraklar 3-4, hepsi tabanda, 10-25 X 1-2 (-3) cm, tabanda dar, oblong lanseolat, çıplak, kenarları düz ya da hafif skabroz, skapustan kisa. Spata 1-1.5 cm boyunda, 2-3 valvli, valvler ovat, akut, soluk pembe renkli, saydam, kalıcı. Umbella 3-4 cm çapında, sık çok çiçekli, yarı küresel; pediseller ince 2-3 $\mathrm{cm}$ uzunlukta, hemen hemen eşit. Perigon yıldız şeklinde; tepaller 5-6 X 1-1.5 mm, lanseolat, obtus. Filamentler perigondan kısa veya hemen hemen perigona eşit, tabanda geniş ovat, tepeye doğru subulat, beyazımsı pembe renkli; anterler erguvani. Ovaryum obovoid; stigma hafif üç loblu. Kapsül $5 \mathrm{~mm}$ boyunda, ovoid; tohumlar 2-2.5 $\mathrm{mm}$, siyah, hemen hemen böbrek şeklinde. Haziran ayında çiçek açar. 1300-1900 m'ler arası dere kenarlarında, nemli ve çayırlık yerlerde yetişir.

Yayılışı: Suriye, Türkiye (Toroslar).

İncelenen örnekler: C6 ADANA: Osmaniye, Zorkun Yaylası, çayırlık yerler, 1550 $\mathrm{m}$, Коуити ve ark., AEF 2153!

Karyotipi: $2 \mathrm{n}=16$. AEF 2153 nolu örneğe ait bitkilerin kromozomları sayılmıştır. Diploid bir türdür. Karyotipi metasentriksubmetasentrik kromozomlardan oluşmuştur. 8 nolu submetasentrik 
kromozom çifti her iki kısa kolunda da satellit taşır. İncelenen diğer türlerden kromozomlarının daha küçük oluşu ve 8 nolu kromozom çiftinin submetasentrik oluşu ile farklıdır (Şekil 2 c).

$\mathrm{Bu}$ türün kromozom sayısı ve morfolojisi ilk kez bu çalışmada verilmektedir.

A. lycaonicum soğanının soğancık taşıması, tepallerinin beyazımsı pembe renkli ve lanseolat oluşu ve ovaryumunun obovat şekli ile ayırtedilebilen bir türdür.

4. A. chrysantherum Boiss.et Reut. in Boiss.F1.Or. 5: 280 (1882). Şekil 1 e.

Syn.: A. reflexum Boiss.et Reut. in Boiss., 1.c: 281 (1882).

Soğan 2-4 cm çapında, ovoid, soğancıksız; dış tunika gri-siyah renkli. Skapus 30-80 cm boyunda, dik, silindirik. Yapraklar 2-3 (-6), hepsi tabanda, 10-25 X 5-20 mm, linear-lorat, kenarları skabroz, gövdeden kısa. Spata 2-4 valvli, valvler ovat, kısa akuminat, umbelladan kısa, sonradan geriye kıvrık. Umbella 3-6 cm çapında, çok çiçekli, yarı küresel; pediseller ince, $1.5-3 \mathrm{~cm}$ uzunlukta, hemen hemen birbirine eşit boyda, çiçeklerin ya hepsi sarı ya da bazen ortadakiler kırmızı renkli. Perigon çiçek açma zamanında yıldız şeklinde, hemen sonra geriye kırık; tepaller 2-2.5 X 0.5-0.6 mm, linear, obtus veya akut. Filamentler 2-3 mm uzunlukta, basit, içtekiler daha geniş; anterler hemen, hemen filamentlere eşit boyda, sarı renkli. Ovaryum basık küresel, stilus filamentlerden daha kısa, stigma hafif üç loblu. Kapsül 5-6 mm boyunda, 6-7 $\mathrm{mm}$ eninde; tohumlar 3.5-4 $\mathrm{mm}$, basık, üzeri papilli. Bitki Mayıs-Haziran aylarında çiçek açar. 1000 1750 m'ler arası kuru yamaçlarda veya tarlalarda yetişir.

Yayılışı: Kuzey-Batı İran, Kafkasya, Türkiye (Güney ve Doğu Anadolu).

İncelenen örnekler: C6 ADANA: Osmaniye-Fevzipaşa arası, Nur Dağı, kuru yamaçlar, 1000 m, Koyuncu ve Coşkun, AEF 2148!

Karyotipi: $2 \mathrm{n}=16+1$. AEF 2148 nolu örneğe ait bitkilerin kromozomları incelenmiştir. Bitki diploiddir ve bir adet ekstra kromozom (B kromozom) gözlenmiştir. İncelediğimiz örnekler arasında B kromozomu taşıyan tek türdür. Karyotipini metasentrik ve submetasentrik kromozomlar oluşturur. 8 nolu submetasentrik kromozom çiftinden 1 tanesinin kısa kolunda satellit gözlenmiştir (Şekil 2 d). 
$\mathrm{Bu}$ türe ait daha önce yapılmış kromozom sayısı ve özelliklerini bildiren bir çalışmaya rastlanmamıştır.

A. chrysantherum umbellasında ortada kırmızı, çevrede sarı çiçeklere sahip olması, tepallerinin geriye kıvrık ve anterlerin filentlerle eşit boyda oluşu, ovaryumun basık küresel şekli gibi özellikleri ile kolay tanınabilen bir türdür.

5. A. cardiostemon Fisch. et C.A.Mey. in Ind.Sem.Hort. Petrop.6: 43 (1840). Şekil 1 d.

Syn. A. trilophostemon Bornm.in feddes Rep.10: 238 (1911).

Soğan 1.2-2.5 cm çapında, ovoid veya hemen hemen globoid; soğancık yok; dış tunika koyu gri veya siyahımsı renkli. Skapus 20-50 $\mathrm{cm}$, dik, silindirik. Yapraklar 2-4, hepsi tabanda, 6-20 cm X 3-10 ( - 20) $\mathrm{mm}$, linear veya linear-lanseolat, çıplak, kenarı hafif skabroz, skapustan kısa. Spata 2-3 valvli, 10-15 mm, ovat, kısa akuminat, sonradan geriye kıvrık, beyazımsı mor renkli. Umbella 2-3 cm çapında, çok çiçekli, sık, hemen hemen küresel; padiseller 10-15 mm uzunlukta. Perigon çiçek açma zamanında yıldız şeklinde, tepaller sonradan geriye doğru kıvrık, 3.5-4.5 X $0.6 \mathrm{~mm}$, koyu şarap renginde, linear, obtus. Filamentler tepallere eşit veya ondan az kısa, koyu şarap ranginde, tabanda birbirleriyle ve tepallerle birleşik, diş filamentler subulat, içtekiler dıştakilerin üç katı genişlikte ve yanlarda kısa küt çıkıntılı; anter ve filamentler vişne çürüğü renginde, anterler 1.5-2 mm. Ovaryum sapsiz, hemen hemen küresel, stilus filamentlerden biraz kısa, stigma tam. Kapsül küresel, $5 \mathrm{~mm}$ çapında, tohumlar 3-3.2 mm, hafif basık, üzeri papilli ve kırışık. Bitki Haziran'da çiçek açar. 900 ile 2750 m'ler arası kuru yamaçlarda yetişir.

Yayılışı: Kuzey-Batı İran, Kafkasya, Türkiye (Doğu ve Güney Anadolu).

İncelenen örnekler: C6 ADANA: Osmaniye-Fevzipaşa arası, Nur Dağı, açık kuru yamaçlar, 1000 m, Koyuncu ve ark., AEF 2152!

Karyotipi: $2 \mathrm{n}=16$. AEF 2152 nolu örneğe ait bitkilerin kromozom özellikleri incelenmiştir. Diploid olan bu türün karyotipinde, 1-7 nolu kromozom çiftleri metasentrik ve submetasentrik, 8 nolu kromozom çifti ise akrosentriktir. Akrosentrik kromozom çift kısa kolunun her ikisinde de satellit taşır (Şekil 2 e). 
Daha önce de yapılan bir çalışmada (6) Türkiye'den toplanan bu türe ait örneklerin kromozom sayısı $2 \mathrm{n}=16$ olarak verilmiştir.

Bu tür iç filamentlerinin orta kısmında, iki yanda kısa ve küt birer çıkıntının varlığı ve tepallerinin koyu şarap rengi ile kolayca ayırt edilebilen bir türdür.

6. A. karamanoglui Koyuncu et Kolim., Isr. Jour. Bot., 27: 93 (1978). Şekil $1 \mathrm{f}$.

Soğan 1-1.5 cm çapında, hemen hemen küresel; soğancıksız; dış tunika ince, gri renkli. Skapus 15-30 cm boyunda, silindirik, erguvani renkli. Yapraklar 1-2, 10-17 X 0.8-1.4 cm, hepsi tabanda, dar lanseolat veya linear, çıplak, kenarları hafif skabroz. Spata $1 \mathrm{~cm}$ uzunlukta, 2-3 parçalı, pedisellerden kısa, tabanda ovat, tepesi akut, kalıcı. Umbella 3-4 cm çapında, yarıküresel, çok çiçekli; pediseller 1.2-1.6 cm uzunlukta, hepsi eşit boyda. Perigon yıldız şeklinde, tepaller 13-16 X 2.5-3 mm, beyaz, orta damar yeşil, lanseolat, tepesi akuminat. Filamentler $4 \mathrm{~mm}$, perigonun 1/4'ü kadar uzunlukta, basit, subulat; anterler koyu erguvani renkli. Ovaryum siyah ya da koyu erguvanı, tepesi basık, hemen hemen küresel veya obovat, sapsız; stilus filamentlere eşit, stigma tam. Kapsül küresel, $5 \mathrm{~mm}$ çapında; tohumlar $3 \mathrm{~mm}$ büyüklükte, üzeri karışık ve papilli. Bitki Nisan ayında çiçek açar. Kuru yamaçlar ve çalılıklar arasında yetişir.

\section{Yayılışı: Endemik}

İncelenen örnekler: C6 ADANA: Osmaniye-Fevzipaşa arası, Nur Dağı, 800 m, Koyuncu, AEF 5688!

Karyotipi: $2 \mathrm{n}=16$. AEF 5688 nolu tip örneğine ait bitkilerin kromozom sayısı ve morfolojisi incelenmiştir. Bitki diploidtir. Temel kromozom sayıs $\mathrm{X}=8$ dir. Karyotipi, 1-7 nolu kromozom çiftleri metasentrik-submetasentrik, 8 nolu kromozom çifti ise akrosentriktir. Satellit gözlenmemiştir (Şekil 2 f).

1978 yılında yeni olarak isimlendirilen bu türün karyotipi ilk kez verilmektedir.

Güneydoğu Anadolu, Suriye ve Filistinde yetişen $A$. aselepiadeum Bornm. türüne yakın olan bu tür tepallerinin uzun, lanseolat-akuminat, stamen boylarının kısa ve anterlerin koyu erguvani rengiyle kolayca ayırt edilir. 


\section{ÖZET}

Güney Anadolu Bölgesinden toplanan ve Melanocrommyum seksiyonu içerisinde yer alan $A$. nigrum L. $2 \mathrm{n}=16$, A. stenopetalum Boiss. et $\mathrm{Ky} \cdot 2 \mathrm{n}=16$, A. lycaonicum Sieche $2 \mathrm{n}=16$, A. chrysantherum Boiss. et Reut. $2 \mathrm{n}=16+1 \mathrm{~B}$, A. cardiostemon Fisch.et C.A.Mey. $2 \mathrm{n}=16$ ve A. karamanoglui Koyuncu et Kolim. $2 \mathrm{n}=16$, türlerinin morfolojik özellikleri, yayılışları ve karyotipleri incelenmiştir.

İncelenen tüm türlerin mitotik kromozom sayıları $2 \mathrm{n}=16^{\prime} \mathrm{d} 1 \mathrm{r}$. Sadece $A$. chrysantherum türü bir B kromozomu taşımaktadır. Bu türlerin karyotipleri birbirine benzer ve 7 çift metasentrik-submetasentrik kromozom ile bir çift akrosentrik kromozomdan oluşmuştur. Akrosentrik olan kromozom çifti kısa kollarının ya ikisinde ya da birinde Satellit taşır. Sadece A. karamanoglui'nin karyotipinde Satellit gözlenmemiştir.

\section{SUMMARY}

Morphological characteristics, distributions and karyotypes of six species, A. nigrum L. $2 \mathrm{n}=16, A$. stenopetalum Boiss. et Ky. $2 \mathrm{n}=16$, A. lycaonicum Siehe $2 \mathrm{n}=16$, A chrysantherum Boiss. Reut. $2 \mathrm{n}=16+$ 1B, A. cardiostemon Fisch, et C.A.Mey. $2 \mathrm{n}=16$ and A. karamanoglui Koyuncu et Kolim. $2 \mathrm{n}=16$, collected from South Anatolia have been reported.

All of them had a mitotic chromosome number of $2 \mathrm{n}=16$ and the karyotypes were very similar (Fig. 2a-f), consisting of seven pairs of metacentric-submetacentric chromosome and one pair of acrocentric chromosomes. Satellites were observed on one or both of the short arms of acrocentric pair in all investigated species except $A$. karamanoglui.

\section{LITERATÜR}

1- Wendelbo, P., Some distributional patterns within the Flora Iranica Area, in P.H. Davis et al., Plant life of South-West Asia, 29-41, Univ. Press, Aberdeen (1971).

2- Özhatay, N., J.Fac.Pharm. Istanbul, 18 (Baskıda).

3- Levan, A., et al., Fredga, K., Sandberg, A.A., Hereditas 52, 201-220 (1964). 
4- Levan, A., ibid. 20: 289-330 (1935).

5- Dietrich, J., Inf.Ann.Caryosystem. et Cytogmet., 33-34 (1969).

6- Pedersen, K. and Wendelho, P., Blyttia 24: 307-313 (1966).

7- Dietrich, J., Inf.Ann.Carycsystem. et Cytogenet., 23-26 (1967).

8- Garbari, F. and Tornadore, N., Informatore Bot.Ital. 2: 74-82 (1970).

9-Johson, M.A.T., Ann.Musei Goulandris 5: 107-119 (1982).

10- Mouterde, P., Nouvelle Flora du Liban et de la Syrie, Tome Prämier Texte, 283, Beyrouth (1966). 